\title{
The Pedagogy Of Postgraduate Research Supervision And Its Complexities
}

\author{
Mutendwahothe Walter Lumadi, North West University, Mafikeng Campus, South Africa
}

\begin{abstract}
This article attempts to clarify the role of supervisors in guiding postgraduate research students and the challenges and complexities encountered in the process of supervision. In the analysis and interpretation of data, it became evident that supervision of postgraduate research students varies enormously, depending on the subject area, the background and needs of the student, and the work patterns and personalities of both the student and the supervisor.
\end{abstract}

\section{BACKGROUND AND INTRODUCTION}

(8)

upervision of postgraduates is viewed as the normal path for entry into the research and academic community. The preparation for, engagement in and successful emergence from the postgraduate research uniquely epitomizes the transition from non-academic to academic status. The rite of passage represented by the postgraduate research process is the very point at which the academic system reproduces itself. Effective research supervision is at the centre of successful postgraduate research, yet it is a teaching learning process poorly comprehended.

Grant (2003:25) is of the opinion that students experience the process as complex and unstable. Supervision of postgraduate research is a process involving complex academic and interpersonal skills. These skills range from guidance of title selection, research methodology, data collection techniques, data analysis and interpretation, conclusion and recommendation and finally publication of the research product. In the process of research supervision, there are times where the supervisor becomes confused and irritated with the progress of the student. The student on the hand is upset with the guidance he receives from the supervisor. Some of the students even go to an extent of throwing in the towel.

\section{METHODOLOGY IN THE STUDY}

In this study, a qualitative approach was followed. Denzin and Lincoln (1999:166) state that qualitative research is multi-method in focus, involving an interpretive, naturalistic approach to its subject. It affords uncontrolled observation. The researcher does not attempt to manipulate the programme or its participants for purposes of the evaluation. It is ground discovery-oriented, explanatory, expansionist and descriptive. It is also process oriented and affords valid, real and deep data. It assumes a dynamic reality and looks at things holistically. (Baxter \& Tight, 2001:65). In this research, 40 respondents who participated in the study were randomly sampled from their institutions of Higher Learning (See table 1.1 for respondents who are consisted of students and supervisors).

From the 20 respondents, 10 were registered for Masters whilst the other 10 were for Doctoral studies. The remaining 20 respondents were supervisors who are more knowledgeable and experienced in postgraduate research supervision. All respondents are from the following countries in the African continent; Botswana, Lesotho, Namibia, South Africa and Swaziland. Each country was represented by 08 respondents (04 students and 04 supervisors apiece). Table 1.1 is comprised of both male and female respondents who were fully involved when collecting data. For data collection, both interviews and questionnaires were used as research instruments for the study. 
Table 1.1: Respondents (students and supervisors)

\begin{tabular}{|c|c|c|c|c|}
\hline Country & \multicolumn{3}{|c|}{ Number of Respondents } & Total \\
\hline & Students & Supervisors & 8 & $20 \%$ \\
\hline BOTSWANA & 4 & 4 & 8 & $20 \%$ \\
\hline LETSOTHO & 4 & 4 & 8 & $20 \%$ \\
\hline NAMIBIA & 4 & 4 & $\mathbf{8}$ & $\mathbf{2 0} \%$ \\
\hline SWAZILAND & $\mathbf{4}$ & $\mathbf{4}$ & $\mathbf{8}$ & $\mathbf{2 0 \%}$ \\
\hline
\end{tabular}

\section{FINDINGS OF THE STUDY}

Various complexities and challenges were identified in the study (See figure 1.1 for supervisors' views regarding challenges encountered during the supervision process).

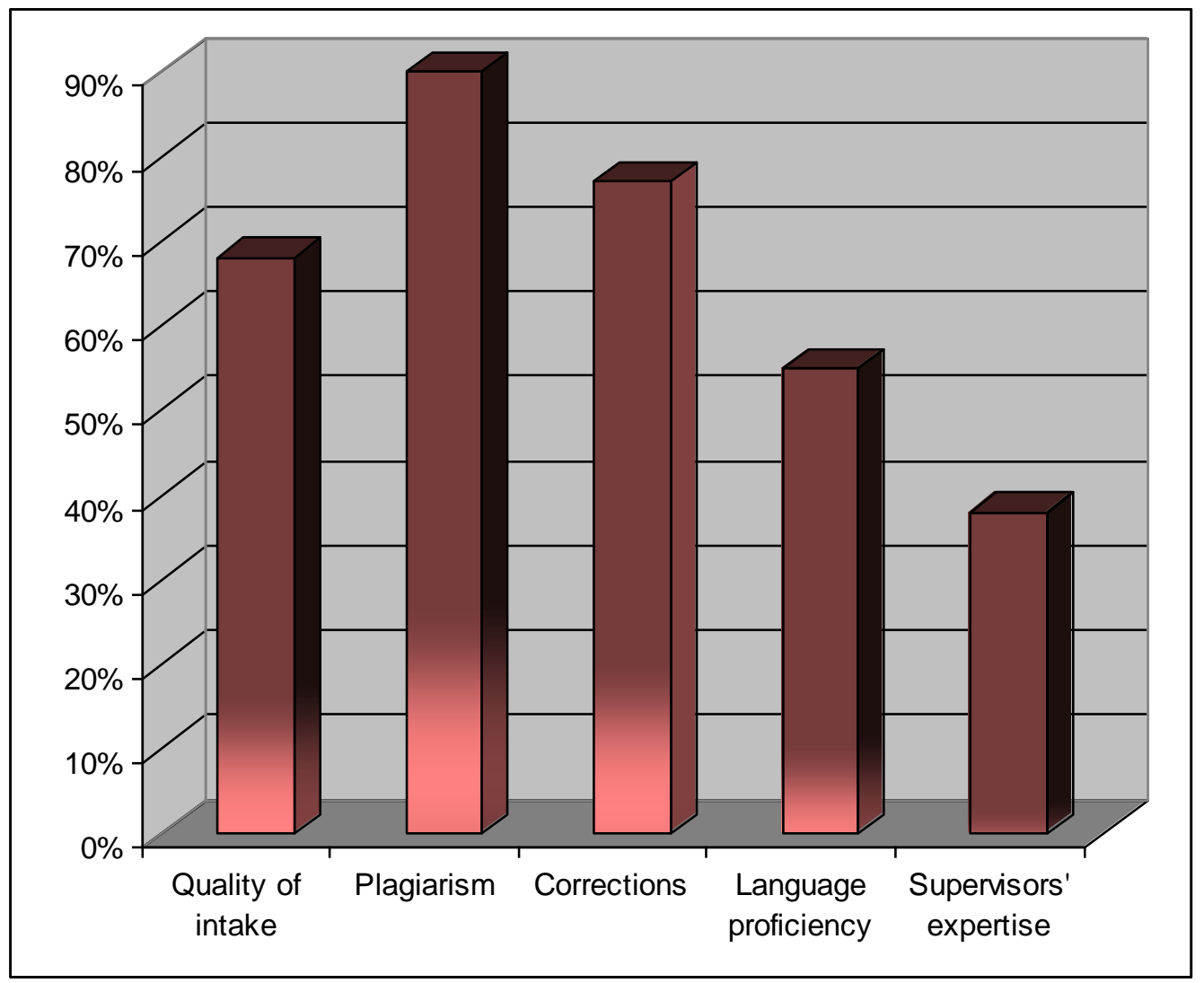

Figure 1.1 Supervisors' views regarding challenges

\subsection{Supervisory Relationship}

Dinham and Scott (1999), Knowles (1999) and Wisker and Sutcliffe (1999) view the relationship with supervisors as a key factor in study success. The most important ingredient in supervision is the healthy relationship between the two parties namely, supervisor and student. This relationship is compared to a rite of passage, an apprentice or marriage in community of property. In each of these relationships, many factors contribute to its 
success. Here, too, the student-supervisor relationship is affected by many issues requiring the supervisor to devote the undivided attention. The supervisor may have so many students all with different personalities, diverse cultures, research constraints and different research needs and interests. The relationship between the two parties should purely be of pedagogic nature and not familial or intimate relationship.

Any personal relationships that may alter this pedagogic relationship may constitute a conflict of interest. Research conducted shows that female students are reportedly most affected by interpersonal relationship factors while male academic factors were more prominent (Seagram, Gould \& Pyke, 2000, and Lussier, 1998). About 80\% of the female students mentioned that male supervisors who lack professional etiquette force these postgraduates into sexual relationship (See figure 1.2 of students' views pertaining supervisory challenges). Open and frank discussions are encouraged between the supervisor and the student from the onset to avert potential squabbles which might be detrimental to the study.

\subsection{Quality Of Intake}

In South African institutions of Higher Learning, the Honours degree is a prerequisite for Masters Registration. The Honours degree follows after the first undergraduate degree which has duration of three years. Some of the junior degrees have a programme of 4 years. In such cases, Honours is inbuilt and the student can register for Masters on successful completion of the programme. Although there are admission requirements which may range from Honours degree, average pass mark of $65 \%$ and Recognition of Prior Learning, there are exceptional cases which may be considered.

In this study, $86 \%$ of supervisors reported that students who do not meet the requirements struggle in the completion of their Masters' programme. Where there is a structured Masters, students finish their course work but encounter serious problems in writing their dissertations. (See figure 1.1 of supervisors' views regarding supervisory challenges). As a result, such students end up being deregistered or given certificates for postgraduate diplomas. Chairpersons of Higher Degrees Committee are supposed to take this issue of quality seriously during the selection process to avoid high dropout rates.

\subsection{Supervisor's Expertise}

During the interviews, it became evident that supervisors for postgraduate research students are appointed by the relevant director in the Faculty in consultation with the Dean. In some institutions, the Head of Department or the Higher Degrees Committee is in charge of appointment of these supervisors. Prior appointment of the supervisor, the concerned committee ensures that it assigns a competent and well grounded supervisor who will be able to guide the student to completion of the study. This supervisor should also have research interests appropriate for the research. Knowledgeable supervisors provide guidance to students in the choice of a researchable topic, problem identification, research design and methodology, data collection techniques, data analysis and interpretation and even recommendations. An expert is the first port of call for guidance in all matters of sound research practice. In general, supervisors should monitor student progress and ensure that they perform adequately. They should also help to keep their research students on track and on time, and also develop an expectation of timely submission.

However, there are instances where supervisors may claim to be knowledgeable in certain research areas. Unfortunately students who are allocated to them suffer academically because they do not receive proper guidance at all. In this research, $74 \%$ of postgraduates complained about supervisors who cannot advice them about the nature and techniques of research, and about the required standard for the qualification. Although these supervisors are supposed to be accessible to postgraduate research students at appropriate times when advice is sought, they are hardly available. Instead they even provide destructive criticism as feedback of the student's work. (See figure 1.2 for further details). This discourages students in conducting their research. 


\subsection{Corrections And Feedback}

Supervisors give written as well as oral feedback on any submitted work within a reasonable period of time after submission. This kind of feedback normally contains constructive criticism which enables the candidate to be aware of potential shortcomings. It is the responsibility of the student to seek and accept advice. This does not mean a slavish adherence to a supervisor's ideas but to accept that supervisors do have expertise in research supervision and that their advice should be taken into account. During the interviews, $69 \%$ (as reflected in figure 1.1) of supervisors indicated that $77 \%$ of postgraduate students are adamant in making corrections. There are instances whereby they ignore the changes required by the supervisor.

Instead of effecting corrections to the supervisors' satisfaction, they still submit the same work without effecting corrections or make minor corrections. This is frustrating to the supervisor who spends sleepless nights trying to make sense of what is written by the student. Once the supervisor realizes that he is reading the same work that he marked without corrections being effected by the student, it results in unnecessary conflict. The primary responsibility of the student is to pursue their research studies, with dedication and according to the highest standards of their discipline, taking due account of the advice and constructive criticism offered by their supervisors. Students on the other hand, allege that supervisors take ages to give them feedback (see figure 1.2 for details).

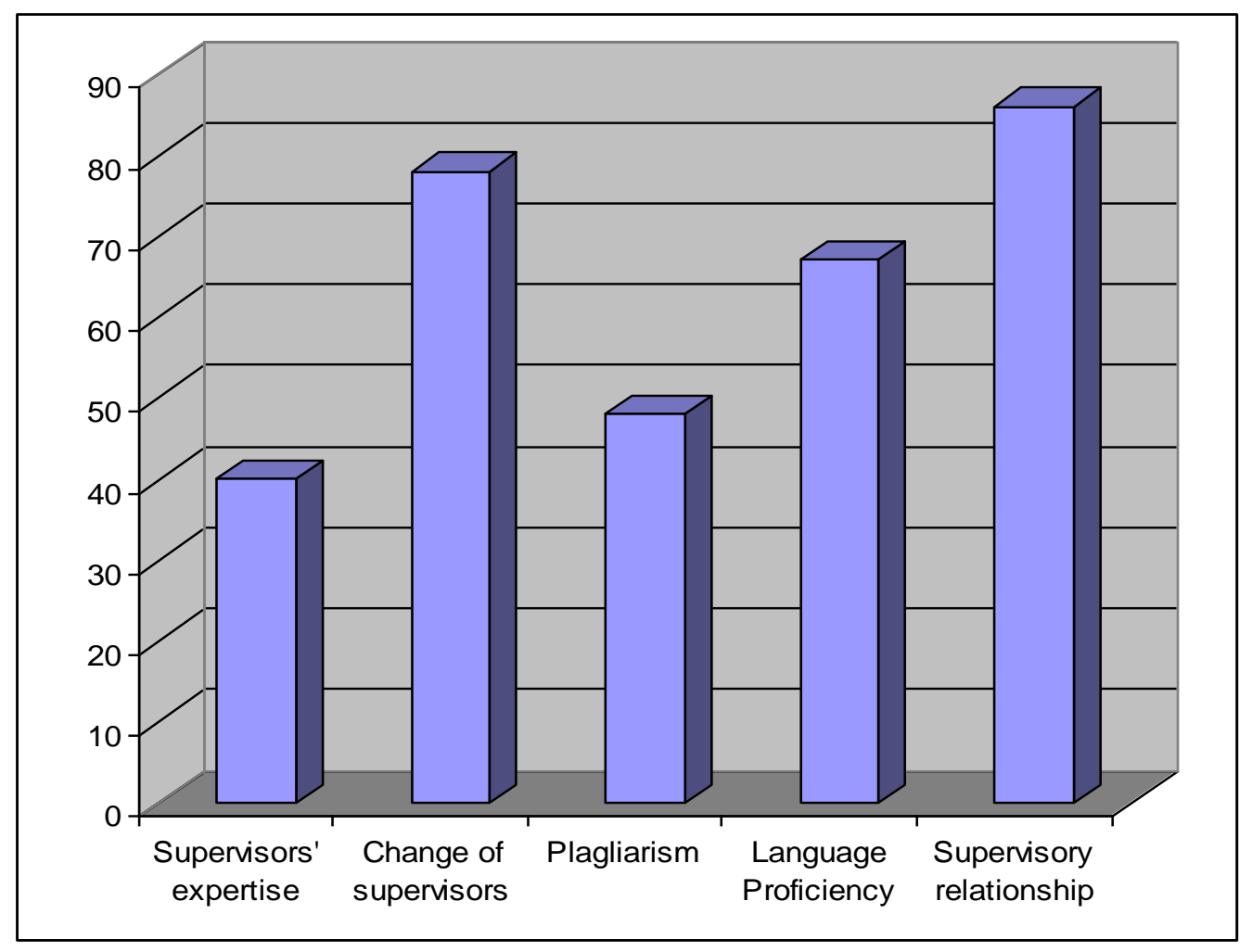

Figure 1.2 students' views regarding challenges

\subsection{Language Proficiency}

Questionnaires' responses show that students who conduct research in English as their second language experience problems in writing up their research dissertations and theses in English. An analysis of figure 1.2 portrays this picture. English becomes a barrier to them when reviewing literature, analyzing and interpreting data. Supervisors spend most of the time editing the study instead of guiding the student. It is taxing to supervisors 
because most students lack understanding of the rhetorical and structural requirements for Masters and Doctoral research.

This view is strongly supported by Bitchener and Basturkmen (2006) who conducted research in English as a stumbling block to most doctoral students writing theses in English as a second language. An enhanced understanding of both dissertation and thesis writing experience will offer useful insights to inform supervisors engaged in postgraduate research with students who have limited English proficiency. It is imperative for postgraduates to articulate their views and concerns in a way that could be understood by the academic community.

\subsection{Change Of Supervisors}

Under no circumstances can the institution guarantee continuity with a particular supervisor throughout the duration of Masters or Doctoral programme. In exceptional circumstances, alternative supervisory arrangements may be warranted to cater for the student. The analysis and interpretation of questionnaires show that in a situation where there are valid reasons, students may be allowed to change supervisors. These reasons may vary from long illness, death or resignation of supervisor, changing the research field which may warrant expertise, unhealthy supervisory relationship between the supervisor and the student, and laziness on the part of the supervisor who does not have time for the student, or supervisor's heavy workload which may disadvantage the student. There are instances where the student keeps on submitting the work to the supervisor without any timeous feedback (for details regarding this challenge see details in figure 1.1). Sometimes the supervisor takes long to return the student's work.

$60 \%$ of postgraduate students stated in the questionnaires that they are given opportunities to comment on the quality of supervision during the course of their dissertation and thesis preparation. These students also raised concerns relating to supervisors' poor performance. They further mentioned that as soon as the student lodges complain to the School Director or Head of the section, the student may be changed from the supervisor for fear of victimization. (See figure 1.1 for further details and analysis). When a new supervisor is assigned to a student, the School Director must ensure that the new supervisor familiarizes himself with the roles and responsibilities of the supervisor. This supervisor should be competent and experienced about supervisory procedures required by the institution in general and the Faculty in particular.

\subsection{Scholastic Dishonesty}

Scholastic dishonesty or academic misconduct entails plagiarism, collusion, or cheating on any examination or classroom assignment (Stoll \& Fink, 2000:196). Edmans and Kowaski (2004:01) are of the opinion that using the words or facts from a source without giving the source for the information and wording is termed plagiarism. As paraphrases are assumed to be one's wording, if one's phrasing is too close to that of the original passage, one is in effect taking the source's words without crediting them. The case of plagiarism is rife at most institutions of Higher Learning. It became evident from both interviews and questionnaires that, $90 \%$ of respondents who happened to be supervisors reported that students falsify data, they present data of reports and projects as if it is their own while it belong to others. Obtaining data in an unscrupulous manner is also common to postgraduates. They copy passages from books, articles, projects, dissertations and theses without acknowledging the author.

Technology makes it a bit difficult for the supervisors to figure out as to whether the students might have plagiarized or not. Some cut and paste information downloaded from the internet. In some of the institutions, it was reported that doctoral students who had already graduated were also involved in plagiarism. In two institutions, the respondents indicated that graduates translated the theses and dissertations from one language to the other. Cases of translation from French to English, Spanish to German and Dutch to Afrikaans were reported. It was a disgrace when the degrees were withdrawn in graduation ceremonies. The institutions took a step further by reporting the matter to the police stations as a criminal case. The message was loud and clear to fellow post-graduates students that plagiarism is condemned and whoever that will be apprehended will not escape unpunished. There are cases were students accused of scholastic dishonesty disputed the facts upon which the charges were based, or choose not to waive the right to a hearing before a hearing officer, Deans of Faculties had to take the matter to the Disciplinary 
Committee chairperson who ended up using his discretion. All students who register at universities are subjected to policy and procedures on academic dishonesty.

Institutions recognize that any form or degree of academic dishonesty challenges the principles of truth and honesty, which are amongst the most important foundation principles of universities. Consequently, institutions treat academic dishonesty as a serious violation of academic trust. They penalize all students found to have engaged in such behaviour. They do not compromise the standing of the institutions as a degree conferring authority as this might have an impact on assurance. The insurance of academic honesty within the institutions is a cooperative enterprise of Faculties, students and management. In a nutshell, the above supervisory challenges are reflected in figure 1.3 for respondents' percentages per country.

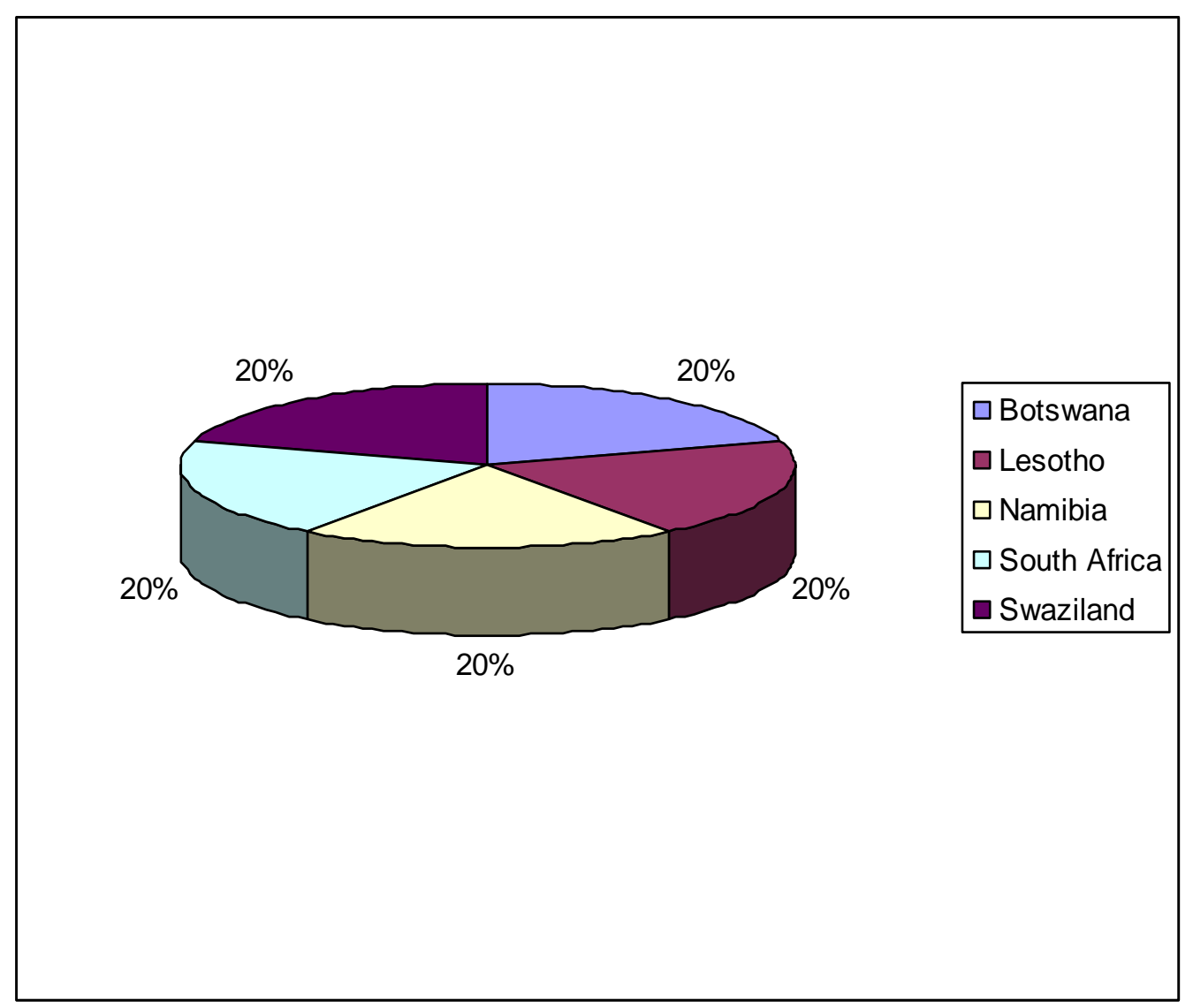

Figure 1.3 Respondents' percentages per country

\section{RECOMMENDATIONS}

Faculties should create a research culture in which a research atmosphere is conducive for academia to contribute meaningfully to postgraduate research supervision. Although the primary aim of most institutions is teaching and learning, it is imperative to point out that academic reputations world-wide are currently built on a research track record, unlike teaching skills. Good researchers are always good postgraduate supervisors. Their skills enable Institutions of Higher Learning to excel in research output and throughput.

- Institutions of Higher Learning should have the responsibility to ensure that appropriate supervision policies are developed and implemented 
- $\quad$ A program of supervision training should be in place

- $\quad$ Quality supervision should be supported financially

- A mutually agreed timetable should be developed. Whenever the two parties meet, both of them should sign the supervision form

- Students should also take the initiatives in raising difficulties associated with the supervision training process

\section{CONCLUDING REMARKS}

Supervision of postgraduate research is a complex and taxing exercise requiring expertise and competence. It is the distinctive teaching and learning process used for graduate research at institutions of Higher Learning world-wide. Supervisors focus specifically on improving students' depth of knowledge and on developing their research skills. The latter mainly includes skills specific to the subject of research and other more generic transferable skills. Good communication is a remedy to both students and supervisors. Its role is of paramount importance in cementing the supervisory relationship. It ensures the effectiveness of supervision and smooth progress of the student's studies. Most institutions of Higher Learning have a number of policy measures in place to safeguard the quality of research supervision. The quality of research supervision is best measured by issues such as the value that postgraduates place themselves on their deliberations with supervisors, supervisors' research expertise and the originality and rigor of the resultant research. The attraction and retention of postgraduates benefits institutions of Higher Learning world-wide financially, capacity and also add to a university's status as a reputable institution.

\section{LIST OF REFERENCES}

1. Baxter, L. Hughes, C. and Tight, M. 2001. How to research. $2^{\text {nd }}$ edition. Buckingham: Open University Press.

2. Bitchener, J. and Basturkmen, H. 2006.Perceptions of the difficulties of postgraduates L2 thesis students writing the discussion section. English for academic purposes. 5, 4-18.

3. Denzin, N.K. and Lincoln, Y.S. 1999. Handbook of qualitative research. Thousand Oaks: Sage Publication.

4. Dinham, S. and Scott, C. 1999. The doctorate: Talking about the degree. Nepean: University of Western Sydney.

5. Edmnans, B. and Kowsaki, D. 2004. Plagiarism. Retrieved 02 December from the World-Wide Web.Pop82d2a.cfm.

6. Grant, B. 2001. Mapping the pleasures and risks of supervision. Discourse: Studies in the cultural politics of Education, 24 (2):175- 190.

7. Knowles, S. 1999. Feedback on writing in postgraduate supervision: echoes in repose - context, continuity and resonance. In supervision of postgraduate research in education. Review of Australian research in Education, 5 eds. A Holbrook and S Johnston. Cold stream: Australian Association for Research in Education.

8. Lussier, T. 1995. Doctoral students at the University of Manitoba: factors affecting completion rates and time to degree by gender and field study. Unpublished masters' study. Winnipeg: University of Manitoba.

9. Seagram, B. Gould, J. Pyke, S. 1998. An investigation of gender and other variables, no time to completion of doctoral degrees. Research in Higher Education, 39 (3): 3 19-335.

10. Stoll, L. and Fink, D.2000. Effecting school change: The Halton approach. School effectiveness and school improvement. London: Wiley.

11. Wisker, G. and Sutcliffe, N. 1999. Good practice in postgraduate supervision. Birmingham: SEDA.

\section{KEY CONCEPTS}

\section{Pedagogy}

Study of teaching methods. 


\section{Postgraduate}

Person who already holds a first degree and who is doing advanced study or research. Although in South Africa an Honours degree is categorized under postgraduate, in this study it refers to Masters and Doctoral degrees.

\section{Institutions of Higher Learning}

Higher Education and Training Institutions. These are universities. It is at these institutions where one can register for a diploma, degree, or do any scientific research.

\section{NOTES}

